Research Article

\title{
Potential and Comparative Tablet Disintegrant Properties of Pectin Obtained from Five Okra Genotypes in Ghana
}

\author{
Frederick William Akuffo Owusu ${ }^{D},{ }^{1}$ Mariam El Boakye-Gyasi ${ }^{(D},{ }^{1}$ \\ Jacob Kwaku Agbenorhevi $(\mathbb{D})^{2}$ Marcel Tunkumgnen Bayor ${ }^{(D)}{ }^{1}$ \\ and Kwabena Ofori-Kwakye $\mathbb{C}^{1}$ \\ ${ }^{1}$ Department of Pharmaceutics, Faculty of Pharmacy and Pharmaceutical Sciences, \\ Kwame Nkrumah University of Science and Technology, Kumasi, Ghana \\ ${ }^{2}$ Department of Food Science and Technology, College of Science, Kwame Nkrumah University of Science and Technology, \\ Kumasi, Ghana \\ Correspondence should be addressed to Mariam El Boakye-Gyasi; melboakye-gyasi.pharm@knust.edu.gh
}

Received 25 April 2021; Revised 31 May 2021; Accepted 10 June 2021; Published 21 June 2021

Academic Editor: José A. Mercado

Copyright (C) 2021 Frederick William Akuffo Owusu et al. This is an open access article distributed under the Creative Commons Attribution License, which permits unrestricted use, distribution, and reproduction in any medium, provided the original work is properly cited.

\begin{abstract}
Okra pectin has been studied as a potential excipient in tablet formulations for pharmaceutical industries. Okra is widely grown and available in Ghana and other parts of the world. The prospective use of pectin from okra genotypes grown in Ghana as tablet disintegrants has not been reported. This study aims to determine the potential and comparative disintegrating properties of pectin from five okra genotypes (Abelmoschus esculentus L.) in Ghana using uncoated immediate release paracetamol tablet formulations. The yield of the pectin from the various genotypes ranged between 6.12 and $18.84 \% \mathrm{w} / \mathrm{w}$. The extracted pectins had $\mathrm{pH}$ ranging from slightly acidic to almost neutral (6.39-6.92). Pectin from the various genotypes exhibited good swelling indexes ('200\%), varying solubility in different solvents, and low moisture content ('20\%). Elemental analysis of the extracted pectin from the various genotypes revealed very low levels of toxic metals and micronutrients. Pectin from the various genotypes was evaluated as disintegrants within concentrations of $5-10 \% \mathrm{w} / \mathrm{w}$ (F1-F18). Their disintegrating properties were compared to that of maize starch BP. All the formulated batches of uncoated immediate release paracetamol tablets (F1-F18) passed the following: uniformity of weight test, uniformity of dimensions, hardness, friability ( $\left.{ }^{<} 1 \%\right)$, and drug content (95-105\%). Significant differences $(p \leq 0.05)$ were observed between the hardness of the maize starch tablets and tablets formulated from pectin of the various genotypes. Pectin from all genotypes other than PC5 exhibited good disintegrating properties $\left(D_{T}^{<} 15\right.$ min) and subsequently passed the dissolution profile test ( $\geq 70 \%$ release in 45 minutes). Tablets formulated with PC5 as disintegrants at all concentrations $(5 \% \mathrm{w} / \mathrm{w}(\mathrm{F} 5), 7.5 \% \mathrm{w} / \mathrm{w}(\mathrm{F} 11)$, and 10\% w/w (F17)) failed the disintegration and dissolution tests. Ultimately, pectins extracted from PC1, PC2, PC3, and PC4 can be commercially exploited as disintegrants in immediate release tablets.
\end{abstract}

\section{Introduction}

Disintegrants are pharmaceutical excipients that are added to immediate release tablet formulations to facilitate their breakup into smaller fragments when in contact with the aqueous medium of the gastrointestinal tract. This aids in faster release and subsequent absorption of the active pharmaceutical ingredient (API) $[1,2]$. Immediate release tablets do not serve their purpose unless they spontaneously and in a predictable manner release their API for absorption in the gastrointestinal fluid. Thus, disintegrants are undoubtedly one of the indispensable excipients needed in achieving the ideal property of immediate release tablets.

Disintegrants can be added to a granule or powder mix either intragranularly, extragranularly, or as a combination of both [3]. Even though several mechanisms of disintegration, such as swelling, particle-particle repulsive force, wicking, and deformation, have been studied, it has also 
been reported that the type of disintegrant, concentration, and mode of incorporation of a disintegrant affects its disintegrating properties and tablet characteristics such as hardness and friability [4]. Disintegrants can be obtained from natural and synthetic sources. The use of natural polymeric excipients in the pharmaceutical sector is increasing on a daily basis over semisynthetic or synthetic excipients due to their low toxicity, availability, cost-effectiveness, and nonirritant nature $[5,6]$.

Conventional sources of disintegrants are known to pose several disadvantages such as tablet softening [7, 8]. Relentless efforts have therefore been channeled into obtaining disintegrants from natural sources such as gums and mucilage as an alternative to conventional sources. This has resulted in the development of novel sources of disintegrants such as khaya gum, Moringa oleifera gum, Azadirachta indica gum, and Sterculia urens gum [9]. However, most of these novel sources of disintegrants are trees and shrubs which have long maturity periods and require large land space for cultivation. There is therefore the need to search for other potential natural sources of disintegrants which will ameliorate the challenges of sources of gums and mucilage as disintegrants. A natural polysaccharide which can be an alternative source of disintegrant due to its water absorbing and swelling properties but has been given less attention is pectin.

Pectin is a family of complex polysaccharides that are found in the primary cell wall and middle lamella of dicotyledons. Unlike the major sources of gums and mucilage, pectin can be sourced from vegetables and lower plants which have shorter maturity periods and require smaller land space for cultivation such as okra. Pectin can therefore be utilized as an alternative source of pharmaceutical excipients at a cheaper cost. The food and beverage industry is already harnessing the properties of pectin as a thickening agent, a gelling agent, and a colloidal stabilizer in their products $[5,10]$. Pectin obtained from the citrus family has been investigated for its binding properties in tablets $[11,12]$. However, currently, there is little or no available literature on the disintegrating properties of pectin. It has been reported that sourcing pectins from plants with short maturity and investigating their disintegrating and other tablet formulation properties will diversify their use in the pharmaceutical industry and attract huge revenues for pharmaceutical industries involved in this research $[13,14]$.

Okra is cultivated in Ghana and many parts of the world mainly for its nutritional value. Its potential for supplying high yields of pectin for pharmaceutical use is a promising area for pharmaceutical scientists to explore [15]. Even though pectin from okra has been investigated and shown to have good drug release modifying properties, there is little information on the potential binding and disintegrating properties of okra pectin [16-19]. Several genotypes of okra are available in Ghana and are widely cultivated in almost every region with variations in duration of cultivation, time of maturation, pod size, and shape [20]. The aim of this current study is to investigate the potential and comparative disintegrant properties of pectin from five (5) okra genotypes cultivated in Ghana using immediate release paracetamol tablet formulations. Investigating the disintegrating properties of okra pectin from different genotypes will provide the needed literature on the potential of pectins to be used as disintegrants and the effect of genotypes on the quality of pectin as a disintegrant. Ultimately, the potential for commercialization of okra being cultivated in Ghana as a pharmaceutical excipient (disintegrants) can be determined from this study.

\section{Materials and Methods}

2.1. Materials. The pods of five okra genotypes (Abelmoschus esculentus L), namely, Penkrumah, Agbagoma, Asha, Sengavi, and Balabi, (PC1, PC2, PC3, PC4, and PC5) were obtained from the Ghanaian market and authenticated at the Department of Horticulture, KNUST, Ghana. Maize starch BP (UK Chemicals) was used as the reference disintegrant in formulations coded F6, F12, and F18. Tragacanth BP (SigmaAldrich), paracetamol BP (Xi'an Henrikang Biotech Co., China), lactose, talc, disodium hydrogen phosphate, and sodium dihydrogen phosphate (VWR Chemicals, UK) were used. All other reagents and chemicals used were of analytical grade.

\subsection{Methodology}

2.2.1. Extraction and Determination of Pectin Yield. The okra pods were cut open and the seeds removed. The separated okra pods were sun-dried, milled to powder, and then stored in zip-lock bags pending extraction. Okra pectin was isolated and extracted at $\mathrm{pH} 6.0$ according to the previous extraction protocol $[20,21]$. The pectin yield was calculated based on the amount of dry okra powder used for the extraction process and the amount of freeze-dried pectin obtained after extraction. The percentage yield $(\mathrm{w} / \mathrm{w})$ was calculated on a dry weight basis [20].

2.2.2. Physicochemical Properties of Extracted Pectin. The $\mathrm{pH}$, moisture content, swelling index, solubility, and elemental contents of pectin from the various genotypes were determined using official methods [12, 22-25].

2.2.3. Drug-Excipient Compatibility Studies. The compatibility between paracetamol and pectin from the various genotypes was determined using a Fourier transform infrared spectrometer (Bruker alpha II). Paracetamol spectra, individual pectin, and physical mixtures of paracetamol and pectin were recorded by scanning in the wavelength region of $4000-400 \mathrm{~cm}^{-1}$ using the FTIR spectrometer. The spectra of the three samples were subsequently superimposed to assess if the main absorption bands present in the drug and pectin are still evident in the physical mixtures.

2.2.4. Preparation of Tablets. Eighteen different batches of granules were prepared by the wet granulation method. The composition of formulated tablets is shown in Table 1 (pectin from various genotypes were used as follows: 
TABLE 1: Composition of formulated batches.

\begin{tabular}{lccccc}
\hline Formulation code & Disintegrant & Disintegrant \\
Pectin & 31.0 & - & $\begin{array}{c}\text { Ingredients (mg/tablet) } \\
\text { Binder } \\
\text { Tragacanth }\end{array}$ & $\begin{array}{c}\text { Diluent } \\
\text { Lactose }\end{array}$ & $\begin{array}{c}\text { Lubricant and glidant } \\
\text { Talc }\end{array}$ \\
\hline F1-F5 & - & 31.0 & 7.5 & 89.0 & 2.5 \\
F6 & 46.5 & - & 7.5 & 89.0 & 2.5 \\
F7-F11 & - & 46.5 & 7.5 & 73.5 & 2.5 \\
F12 & 62.0 & - & 6.5 & 5.5 & 3.5 \\
F13-F17 & - & 62.0 & 6.5 & 58.0 & 3.5 \\
F18 & & & -5.5 & & \\
\hline
\end{tabular}

Paracetamol $(500 \mathrm{mg})$ was used as the active pharmaceutical ingredient (API) in each formulation. Batches F1-F5 contained pectin from the various genotypes in the order PC1-PC5. Batches F7-F11 contained pectin from the various genotypes in the order PC1-PC5. Batches F13-F17 contained pectin from the various genotypes in the order PC1-PC5.

disintegrants at different concentrations: $\sim 5 \% \mathrm{w} / \mathrm{w}(\mathrm{F} 1-\mathrm{F} 5)$, $\sim 7.5 \% \mathrm{w} / \mathrm{w}$ (F7-F11), $10 \% \mathrm{w} / \mathrm{w}$ (F13-F17). A blend of all ingredients except the talc (lubricant and glidant) was mixed in a porcelain mortar. Half of the disintegrant was added intragranularly and the rest extragranularly. Kneading was done using a mucilage of water and the binder until a damp mass was formed. The damp mass was screened through a $2360 \mu \mathrm{m}$ mesh and the wet granules were dried at $60^{\circ} \mathrm{C}$ for 1 hour in a hot air oven. The dried granules were screened through a $1190 \mu \mathrm{m}$ mesh. The granules were kept in airtight containers and stored in a desiccator pending further analysis and subsequent compression into tablets. The angle of repose was determined using the fixed height method. The bulk and tapped densities were used for the determination of compressibility index as well as Hausner's ratio [3]. Talc was incorporated by hand mixing for 5 minutes just before compression. The granules were compressed into tablets using a single punch tableting machine (Saimach press 11/ 37, India).

\subsubsection{Evaluation of Tablet Properties}

(1) Physicomechanical Properties. The physicomechanical properties of formulated tablets such as weight, dimensions, friability, crushing strength, and disintegration times were assessed using Pharmacopoeia methods [22, 26, 27]

(2) Assay. The content of paracetamol in each of the eighteen batches was determined using a reverse-phase chromatographic technique developed and validated in [28] with some modifications. Twenty paracetamol tablets were randomly sampled and weighed accurately and the average weight was recorded. The tablets were crushed to a fine powder and a quantity of the powder equivalent to $0.15 \mathrm{~g}$ of paracetamol was accurately weighed. The powder mixture was dissolved in a mobile phase (methanol 65\%: $0.1 \%$ TFA in water 35\%) with the aid of sonication and then made up to the $100 \mathrm{ml}$ mark with the mobile phase. The solution was filtered through Whatman filter paper (No. 5) into another $100 \mathrm{ml}$ volumetric flask. From the above filtrate, $1 \mathrm{ml}$ was taken in a $10 \mathrm{ml}$ volumetric flask and volume was made up to the mark with the mobile phase; the solution was then filtered using sintered glass filter and loaded in the injector of an Agilent HPLC (1260 with programmable absorbance detector and Agilent Zorbax SB-Phenyl $150 \mathrm{~mm} \times 3.0 \mathrm{~mm} \times 3.5 \mu \mathrm{m}$ column). The sample solution $(1 \mu \mathrm{l})$ was injected at a flow rate of $1 \mathrm{ml} / \mathrm{min}$ and the detection of eluent was carried out at $230 \mathrm{~nm}$. The injection was repeated three times and the peak area of paracetamol was recorded. The average peak area was then used to calculate the amount of drug present using the average peak area of pure paracetamol with the same concentration as a standard. The experimental procedure was repeated for the other batches.

(3) In Vitro Dissolution Test. The Veego UDA-8D USP dissolution apparatus II (paddle apparatus) was used to conduct the dissolution test. Phosphate buffer $(900 \mathrm{ml})$ with a $\mathrm{pH}$ of 5.8 was used for the dissolution test of the tablets. The temperature of the medium was strictly maintained at $37 \pm 2^{\circ} \mathrm{C}$ throughout the experiment. One dosage unit from a batch was placed in each of the six vessels and the stirrers and timer switched on simultaneously. The speed of agitation used was $50 \mathrm{rpm}$. Ten (10) $\mathrm{ml}$ of the dissolution media was withdrawn and filtered at different time intervals of 5, 15, 30, 45, and 60 minutes. An equal volume $(10 \mathrm{ml})$ of fresh medium having the same temperature was replaced at each time to maintain the sink condition in the vessel. Each sample withdrawn was filtered and $0.50 \mathrm{ml}$ of each filtrate diluted to $50 \mathrm{ml}$ with the phosphate buffer. The diluted solution was then assayed spectrophotometrically at $245 \mathrm{~nm}$, using phosphate buffer ( $\mathrm{pH}$ 5.8) in the reference cell. The amount of paracetamol released was then determined from the calibration curve $(y=806.29 x-0.0784$, $R^{2}=0.9995$. The experimental procedure was repeated for the other batches. A graph of percentage drug released against time was plotted to establish the dissolution profile of paracetamol from each batch $[26,29]$.

2.3. Statistical Analysis. The results are presented as the mean \pm standard deviation. Data was analyzed using GraphPad Prism version 6.00 for Windows (GraphPad Software, San Diego California, USA). At 95\% confidence interval, $p \leq 0.05$ was considered significantly different. Dissolution profiles were compared using similarity $(f 2)$ and difference ( $f 2$ ) factors. 


\section{Results and Discussion}

3.1. Extraction and Determination of Physicochemical Properties of the Okra Pectins. All five okra (Abelmoschus esculentus L.) genotypes after extraction produced pectin yields ranging from $6.12 \%$ to $18.84 \% \mathrm{w} / \mathrm{w}$ in the following order PC2 $>$ PC5 $>$ PC $3>$ PC4 $>$ PC1. Pectin yield is known to be affected by the genotype used, the extraction method used, plant source, and maturation stage [20,21]. Since the same extraction protocol was used, the differences in the pectin yield indicate structural variations in the pectin backbone of the various genotypes. Pectin from various genotypes of okra had slightly acidic to neutral $\mathrm{pH}$ (Table 2 ). These $\mathrm{pH}$ values will not cause irritation to the mucosal lining of the gastrointestinal tract. Similarly, these $\mathrm{pH}$ values do not alter the $\mathrm{pH}$ of the medium in which the active ingredient of the dosage form is dissolved and therefore do not affect the release profile of the active ingredient.

The intrinsic swelling properties of pectin from the various genotypes can be used to predict their potential mechanism of disintegration. The swelling capacity of pectin from the various genotypes was in the following order: PC2 $>$ PC5 $>$ PC4 $>$ PC $3>$ PC1 (Table 2). The swelling property of okra pectin is attributed to the high concentrations of D-galacturonic acid polysaccharide backbone [30]. Variations in the genotypes resulted in differences in their swelling indexes. However, the swelling indexes of all the okra genotypes were higher than those reported of pectin from other sources $[12,25]$.

Variations in the chemical properties of pectin from the different genotypes resulted in differences in their solubility profile. This is similar to the results reported for the solubility profile of pectin obtained from mango and apple [31, 32]. The moisture content of powders and granules has an effect on their flow properties; high moisture content can cause granules to clamp together and agglomerate causing them to have poor flow. Microbial growth is also encouraged if moisture contents are high. All the genotypes had their moisture content being less than $20 \%$ and lesser than the moisture content reported for pectin from other sources [12].

Elemental analysis of pectin from different genotypes showed extremely low levels of toxic metals (Figure 1(a)). Micronutrient levels were also within acceptable limits (Figure 1(b)) [27]. This indicates the potential nontoxicity of okra pectin from the various genotypes and their suitability for use as pharmaceutical excipients.

IR spectra of pectin from all the genotypes showed the following characteristic features: stretching within the range of $3100-3600 \mathrm{~cm}^{-1}$ (O-H stretching), bands within the range of $3000-2700 \mathrm{~cm}^{-1}$ (C-H stretching), and bands ranging from 1600 to $1670 \mathrm{~cm}^{-1}$ corresponding to $\mathrm{COOH}$ stretching. These bands were similar to those reported by Kpodo et al. and Alba et al. in the identification of okra pectin [20, 21]. A spectrum of pure paracetamol produces functional groups at $3322.03 \mathrm{~cm}^{-1}$, $3159.39 \mathrm{~cm}^{-1}$ (hydroxyl group, O-H stretching) and $1561.11 \mathrm{~cm}^{-1}, 1504.98 \mathrm{~cm}^{-1}$ (amide II band). The physical mixtures contained all of the two constituents' main bands and showed no peak shifts, indicating the pectins' stability and compatibility with the active pharmaceutical ingredient (Figure 2).

\subsection{Physicomechanical Properties of the Formulated Para-} cetamol Tablets. A summary of the physical and mechanical properties of the formulated paracetamol batches is shown in Tables 3 and 4 .

Based on the results shown (Table 3), the granules for compression generally exhibited good flow properties. The Hausner ratio value ranged from 1.01 to 1.18 suggesting a good and excellent flow of the granules. Carr's index ranged from $2.21 \%$ to $15.87 \%$ which suggests an excellent and good flow of the granules. The angle of repose obtained also ranged from $29.00^{\circ}$ to $33.02^{\circ}$. This shows that the granules had a good flow [3]. Low moisture content of granules, relatively smooth surface of granules, spherical shapes, and adequate size distribution of granules are responsible for the good and excellent flow properties exhibited by the granules. The excellent and good flow property of granules indicates that a glidant concentration of $\leq 1 \%$ will be needed in the formulation of the tablets.

The total tablet weight produced was between $0.620 \pm 0.001$ and $0.639 \pm 0.002$ (Table 4). None of the tablet batches failed the uniformity of weight test $(<2$ tablets $\pm 5 \%$ mean weight, none $\pm 10 \%$ mean weight, $n=20$ ) [25]. The consistent results may be attributed to the good flow properties of the prepared granules, the uniform compression force used in tablet compression, even feeding of granules into the die, and the regular movement of the lower punch to ensure a consistent weight distribution of the tablets [33].

Tablet thickness and diameter are very crucial factors in tablet packaging and aesthetic appeal: tablets which are too thick will affect the ease of blister and plastic packaging and invariably reduce patient compliance $[34,35]$. All the formulated batches had their thickness and diameter within the accepted range of $\pm 5 \%$. This indicates consistency in dimensional characteristics of the formulated tablets in each batch and ultimately good compressional properties of okra pectin.

A tablet's resistance to abrasion, capping, and splitting during transportation and packaging depends on its friability and hardness. Immediate release tablets possessing friable properties may laminate or cap into halves during packaging whiles overly compact tablets may not disintegrate within time to meet the dissolution requirements $[22,26]$. A minimum crushing force of $3 \mathrm{~kg} / \mathrm{f}$ is required of tablets formulated as immediate release [36]. Thus, all the formulated batches will have good resistance to fracture since their crushing strengths were above the minimum value (Table 4) and confirms the suitability of okra pectins as pharmaceutical excipients in the compression of tablets.

Excipients such as disintegrants have been reported to have an effect on the crushing strength of tablets [37-39]. Depending on the physicochemical properties of the disintegrant, increasing the disintegrant concentration may increase the hardness of the tablet and decrease the hardness 
TABle 2: Physicochemical properties of the extracted pectin.

\begin{tabular}{lccccc}
\hline Parameter & & \multicolumn{4}{c}{ Okra genotypes } \\
& PC1 & PC2 & PC3 & PC4 & PC5 \\
\hline Pectin yield (\%) & 6.12 & 18.84 & 11.93 & 7.7 & 13.54 \\
pH & $6.92 \pm 0.010$ & $6.74 \pm 0.006$ & $6.39 \pm 0.012$ & $6.87 \pm 0.006$ & $6.80 \pm 0.010$ \\
Moisture content (\%) & $16.2 \pm 1.20$ & $19.7 \pm 0.5$ & $11.2 \pm 2.0$ & $16.1 \pm 0.6$ & $15.9 \pm 0.00$ \\
Swelling index (\%) & $405.05 \pm 0.045$ & $555.737 \pm 0.015$ & $407.246 \pm 0.009$ & $441.666 \pm 0.020$ & $540.394 \pm 0.010$ \\
Solubility & & & & \\
$\quad$ Hot water & Sparingly soluble & Sparingly soluble & Sparingly soluble & Sparingly soluble & Sparingly soluble \\
Cold water & Sparingly soluble & Sparingly soluble & Sparingly soluble & Sparingly soluble & Sparingly soluble \\
Pet. ether & Practically insoluble & Very slightly soluble & Very slightly soluble & Practically insoluble Very slightly soluble \\
Diethyl ether & Practically insoluble & Sparingly soluble & Slightly soluble & Very slightly soluble Very slightly soluble \\
Methanol & Slightly soluble & Practically insoluble & Very slightly soluble & Slightly soluble & Slightly soluble \\
Ethanol & Very slightly soluble & Very slightly soluble & Very slightly soluble & Slightly soluble & Slightly soluble \\
\hline
\end{tabular}

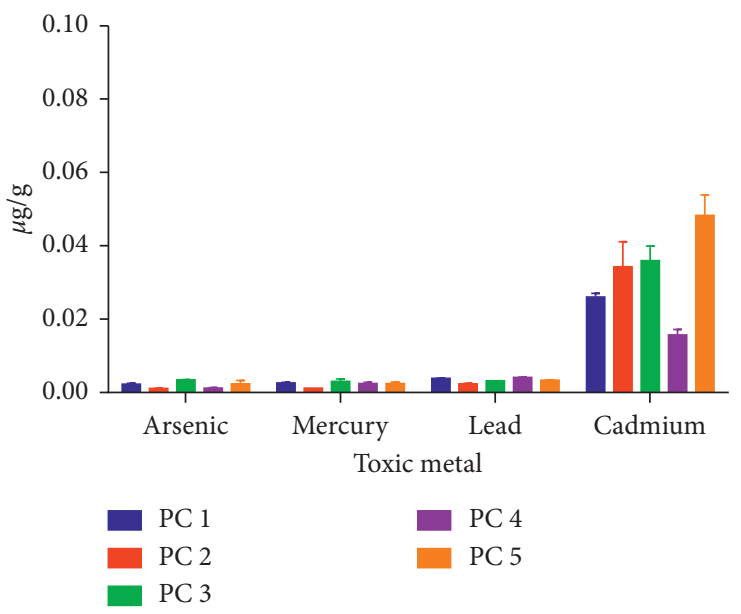

(a)

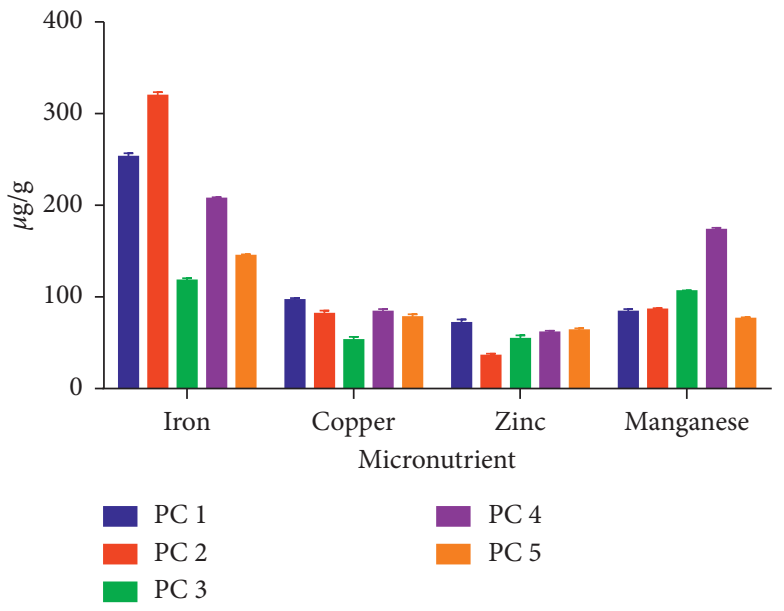

(b)

FIGURE 1: Elemental analysis on pectin from various genotypes; (a) toxic metals and (b) micronutrients.

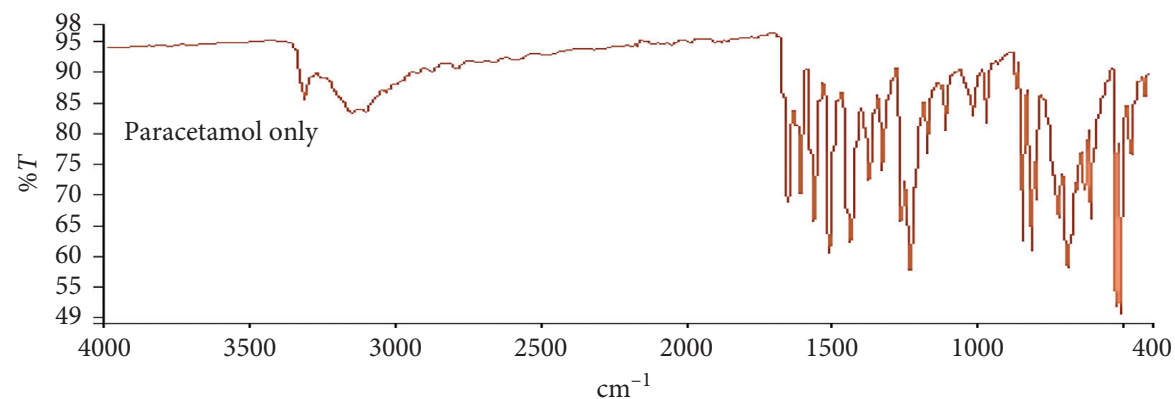

(a)

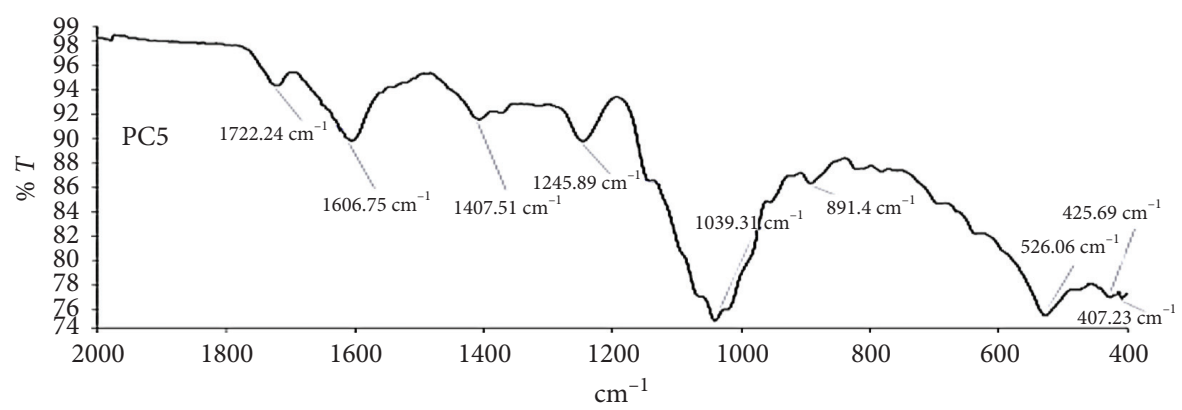

(b)

Figure 2: Continued. 


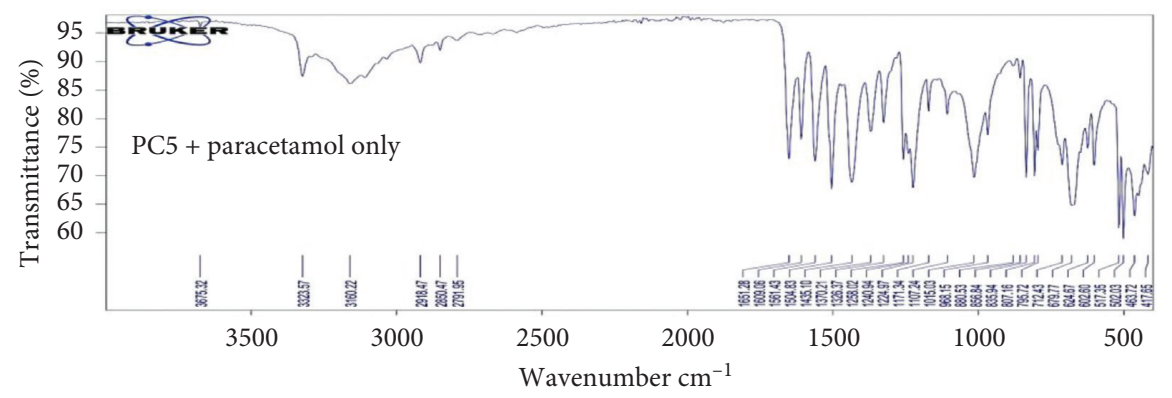

(c)

FIGURE 2: FTIR spectra of pure paracetamol (active), okra pectin (PC5), and the physical mixture of paracetamol and okra pectin (PC5 + active).

TABLE 3: Flow properties of formulated granules.

\begin{tabular}{lccc}
\hline Formulation code & Hausner ratio & Carr's index $(\%)$ & Angle of repose $(\Theta)$ \\
\hline F1 & 1.08 & 7.71 & 29.47 \\
F2 & 1.15 & 13.66 & 31.55 \\
F3 & 1.08 & 7.99 & 29.29 \\
F4 & 1.04 & 2.21 & 30.38 \\
F5 & 1.11 & 9.89 & 30.77 \\
F6 & 1.10 & 15.87 & 29.89 \\
F7 & 1.14 & 13.95 & 33.02 \\
F8 & 1.18 & 15.40 & 28.78 \\
F9 & 1.14 & 12.24 & 28.61 \\
F10 & 1.09 & 8.51 & 28.61 \\
F11 & 1.15 & 15.33 & 28.95 \\
F12 & 1.18 & 15.48 & 30.08 \\
F13 & 1.06 & 5.99 & 30.00 \\
F14 & 1.09 & 7.30 & 30.00 \\
F15 & 1.07 & 6.80 & 30.00 \\
F16 & 1.07 & 6.80 & 30.00 \\
F17 & 1.11 & 7.80 & 30.00 \\
F18 & 1.01 & 10.56 & 29.00 \\
\hline
\end{tabular}

TABle 4: Physical and mechanical properties of paracetamol batches produced using different concentrations of the okra pectin as disintegrant.

\begin{tabular}{|c|c|c|c|c|c|c|c|}
\hline $\begin{array}{l}\text { Formulation } \\
\text { code }\end{array}$ & $\begin{array}{l}\text { Average weight } \\
\text { (g) } n=20\end{array}$ & $\begin{array}{l}\text { Tablet thickness } \\
\qquad(\mathrm{mm}) n=20\end{array}$ & $\begin{array}{l}\text { Tablet diameter } \\
\quad(\mathrm{mm}) n=20\end{array}$ & $\begin{array}{l}\text { Hardness }(\mathrm{kg} / \\
\text { F) } n=6\end{array}$ & $\begin{array}{c}\text { Friability } \\
(\%)\end{array}$ & $\begin{array}{l}\text { Disintegration time } \\
\left(D_{T}\right)(\min ) n=2\end{array}$ & $\begin{array}{l}\text { Drug content } \\
\text { (\%) } n=3\end{array}$ \\
\hline $\mathrm{F} 1$ & $0.630 \pm 0.003$ & $3.70 \pm 0.093$ & $13.07 \pm 0.235$ & $5.60 \pm 0.539$ & 0.330 & $11.40 \pm 0.265$ & $99.61 \pm 0.03$ \\
\hline $\mathrm{F} 2$ & $0.630 \pm 0.001$ & $3.98 \pm 0.073$ & $13.04 \pm 0.009$ & $4.88 \pm 1.308$ & 0.139 & $14.20 \pm 0.398$ & $99.61 \pm 0.07$ \\
\hline F3 & $0.620 \pm 0.001$ & $3.78 \pm 0.145$ & $13.03 \pm 0.015$ & $7.38 \pm 2.46$ & 0.005 & $10.40 \pm 0.447$ & $100.12 \pm 0.01$ \\
\hline $\mathrm{F} 4$ & $0.620 \pm 0.001$ & $3.61 \pm 0.092$ & $13.06 \pm 0.025$ & $5.92 \pm 1.264$ & 0.002 & $8.90 \pm 0.566$ & $99.92 \pm 0.10$ \\
\hline F5 & $0.621 \pm 0.002$ & $3.96 \pm 0.104$ & $13.08 \pm 0.051$ & $6.44 \pm 1.405$ & 0.011 & $19.20 \pm 0.100$ & $99.82 \pm 0.03$ \\
\hline F6 & $0.620 \pm 0.001$ & $3.76 \pm 0.099$ & $13.07 \pm 0.025$ & $4.02 \pm 0.861$ & 0.005 & $9.87 \pm 0.640$ & $99.75 \pm 0.08$ \\
\hline F7 & $0.630 \pm 0.002$ & $3.74 \pm 0.043$ & $13.03 \pm 0.011$ & $6.4 \pm 0.57$ & 0.000 & $10.60 \pm 0.148$ & $99.82 \pm 0.10$ \\
\hline F8 & $0.632 \pm 0.002$ & $3.87 \pm 0.132$ & $13.02 \pm 0.085$ & $4.92 \pm 0.719$ & 0.002 & $9.09 \pm 0.122$ & $99.30 \pm 0.04$ \\
\hline F9 & $0.629 \pm 0.002$ & $3.88 \pm 0.112$ & $13.04 \pm 0.015$ & $8.14 \pm 2.519$ & 0.002 & $11.08 \pm 0.898$ & $97.46 \pm 0.01$ \\
\hline F10 & $0.631 \pm 0.002$ & $3.95 \pm 0.109$ & $13.05 \pm 0.017$ & $8.60 \pm 2.742$ & 0.005 & $12.22 \pm 0.867$ & $98.26 \pm 0.03$ \\
\hline F11 & $0.631 \pm 0.005$ & $3.94 \pm 0.134$ & $13.04 \pm 0.017$ & $6.74 \pm 2.703$ & 0.009 & $19.39 \pm 0.145$ & $99.59 \pm 0.11$ \\
\hline F12 & $0.621 \pm 0.002$ & $3.78 \pm 0.087$ & $13.05 \pm 0.401$ & $4.62 \pm 0.563$ & 0.174 & $9.39 \pm 1.07$ & $99.56 \pm 0.03$ \\
\hline F13 & $0.629 \pm 0.001$ & $3.68 \pm 0.094$ & $13.05 \pm 0.012$ & $6.56 \pm 0.467$ & 0.265 & $10.98 \pm 0.989$ & $99.71 \pm 0.01$ \\
\hline F14 & $0.621 \pm 0.002$ & $3.87 \pm 0.068$ & $13.09 \pm 0.025$ & $6.20 \pm 0.663$ & 0.742 & $8.78 \pm 1.023$ & $99.00 \pm 0.10$ \\
\hline F15 & $0.630 \pm 0.003$ & $3.67 \pm 0.096$ & $13.07 \pm 0.018$ & $7.34 \pm 2.062$ & 0.017 & $10.53 \pm 0.895$ & $97.63 \pm 0.20$ \\
\hline F16 & $0.630 \pm 0.002$ & $3.72 \pm 0.203$ & $13.04 \pm 0.008$ & $3.74 \pm 1.152$ & 0.002 & $10.49 \pm 1.023$ & $99.29 \pm 0.03$ \\
\hline F17 & $0.631 \pm 0.003$ & $3.88 \pm 0.138$ & $13.08 \pm 0.013$ & $7.10 \pm 0.866$ & 0.256 & $25.04 \pm 0.987$ & $101.36 \pm 0.02$ \\
\hline F18 & $0.639 \pm 0.002$ & $3.82 \pm 0.067$ & $13.08 \pm 0.045$ & $7.42 \pm 0.287$ & 0.196 & $9.05 \pm 0.989$ & $99.00 \pm 0.11$ \\
\hline
\end{tabular}


of the tablet or in some cases provide no correlation. The effects of pectin (from the various genotypes of okra) as disintegrants $(\sim 5 \%, \sim 7.5 \%$, and $\sim 10 \% \mathrm{w} / \mathrm{w})$ on the crushing strength of formulated tablets have been illustrated in Figure 3. Pectin from PC1, PC2, and PC5 as disintegrants exhibited similar properties to those of the standard (maize starch BP). There was an increase in the hardness of the tablets prepared from these batches as their concentrations increased. This is similar to studies carried out by [1] on some selected disintegrants. This suggests that for disintegrants exhibiting such properties a careful selection of lower concentrations of disintegrant is needed for the preparation of a tablet with good mechanical characteristics since higher concentrations tend to increase the bonding strength in tablets and can result in very compact tablets. However, PC4 and PC3 showed a reduction in tablet hardness from $7.5 \%$ to $10 \% \mathrm{w} / \mathrm{w}$. This reduction in tablet hardness is also similar to other studies carried out on disintegrants by $[2,37]$ suggesting that, generally, some disintegrants tend to weaken tablet structure when used in higher concentrations. These variations in hardness were further confirmed statistically by carrying out a two-tailed test on the various pectin concentrations with their corresponding standard concentrations. Significant differences $(p \leq 0.05)$ were observed between some concentrations and the standard while, in some cases, there were no significant differences $(p>0.05)$ (Figure 4$)$.

A tablet weight loss not exceeding $1 \%$ of the tablet weight being tested is usually deemed appropriate for pharmaceutical products $[22,26]$. Controlling friability requires accurate control of tablet weight and roughness of tablet surface, good granulation method, good compression method, moisture at low levels, and acceptable concentrations of binders and disintegrants [40]. All the formulated batches passed the friability test (Table 4), indicating that incorporation of okra pectin as a disintegrant does not produce soft tablets, which is a challenge of conventional disintegrants.

Pectin, a natural polysaccharide just as starch, can exhibit potential disintegration property by swelling when it comes into contact with water and this will result in a gradual increase in pressure and stress within the tablet and subsequently break down the tablet. Pectin from PC5 was unable to cause the breakup of uncoated immediate release tablets within the stipulated time range $\left(D_{T}<15 \mathrm{~min}\right)$ at all concentrations (5\% w/w (F5), 7.5\% w/w (F11), and 10\% w/w (F17)) used (Table 4, Figure 5). PC5 may have exhibited poor disintegration properties in uncoated immediate release tablets due to slower rate in the uptake of water and formation of a gel plug after imbibition of water [3, 4, 41]. All the other genotypes exhibited good disintegrating properties $\left(D_{T}{ }^{<} 15\right.$ mins) within the concentrations used (Table 4, Figure 5). Generally, an increase in disintegrant concentration may have two effects on disintegration time: a reduction in disintegration time if the concentrations used are below the optimal concentration or no correlation with disintegration time if the concentrations used are equal to or above the optimal concentration [1, 3, 4, 29]. PC1, PC2, and the standard disintegrant (Figure 5) produced a reduction in disintegration time with an increase in concentration.

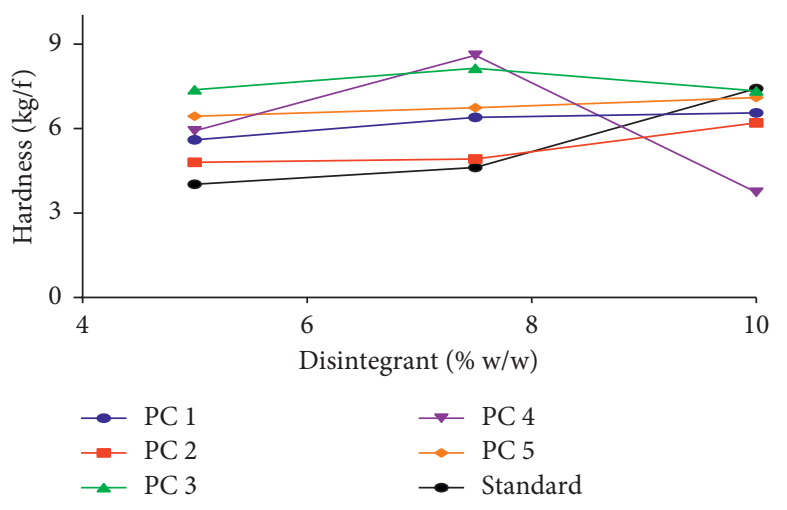

FIGURE 3: Effect of pectin concentrations as disintegrants on tablet hardness.

However, the disintegration times of PC4 and PC3 did not decrease with an increase in concentration indicating that their optimal disintegration times were obtained at $5 \% \mathrm{w} / \mathrm{w}$ (Figure 5). These observations were confirmed by variations in statistical analysis between the disintegration times of the standard disintegrant and the okra pectins (Figure 6).

The dissolution profiles of the paracetamol tablets containing different concentrations of the okra pectin in phosphate buffer $\mathrm{pH} 5.8$ are shown in Figure 7. It was observed that, within 45 minutes of dissolution, all the tablet batches passed the dissolution test ('70\% released) as specified by the British Pharmacopoeia with the exception of F2, F5, F11, and F17. Disintegration precedes dissolution hence disintegrants which are able to cause a faster breakup of immediate release tablets will enhance the dissolution process of the active ingredient and produce tablets with good drug release profiles. PC5 at all concentrations as disintegrants in batches F5, F11, and F17 failed the disintegration test and subsequently the dissolution test and hence will not be suitable as a disintegrant for immediate release tablets. However, the delay in disintegration action of pectin from PC5 may suggest its potential as a good control releasing agent at low concentrations. Pectin from PC2 when used as a disintegrant $(5 \% \mathrm{w} / \mathrm{w})$ in batch $\mathrm{F} 2$ produced a disintegration time very close to the limit of 15 minutes and subsequently resulted in a poor dissolution profile which did not correspond to the expected drug release. An increase in the concentration of PC2 subsequently reduced disintegration time and produced tablets with good release profiles which complied with the standard limit [26] ('70\% drug release in 45 minutes).

Formulations which passed the dissolution profile were then fitted into the difference and similarity factors equations [42-44] and their results are shown in Table 5. From the results obtained, the batches of formulations F4, F7, F8, F13, F15, and F16 had similar dissolution profiles as formulations with maize starch BP incorporated as disintegrant. Thus, at a disintegrant concentration of $5 \% \mathrm{w} / \mathrm{w}$, okra pectin from PC4 was able to release paracetamol from the tablet to a similar extent as maize starch BP. At a disintegrant concentration of $7.5 \% \mathrm{w} / \mathrm{w}$, okra pectins from PC1 and PC2 were able to have similar effects on the release of paracetamol from the formulation as maize starch BP. At a 


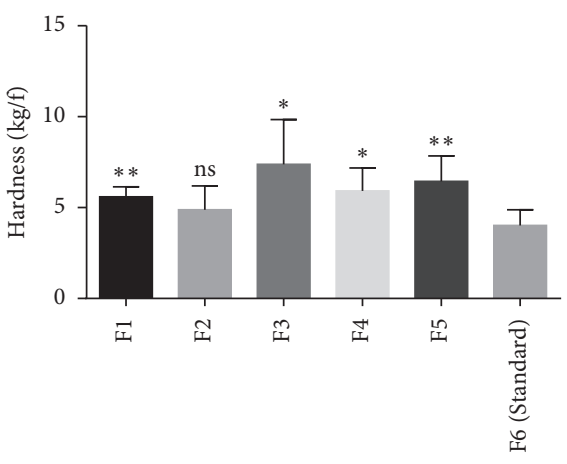

Formulation

(a)

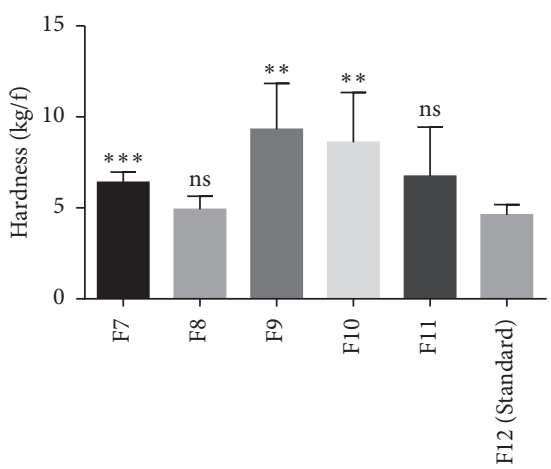

Formulation

(b)

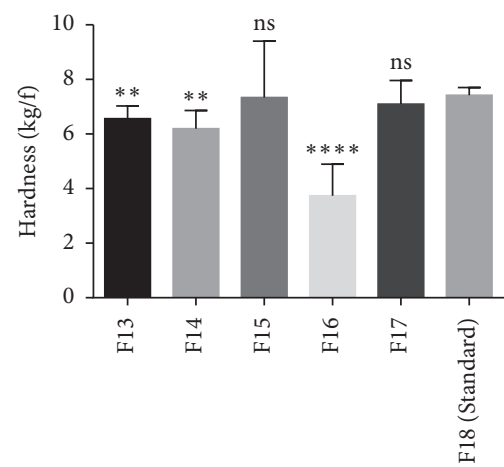

Formulation

(c)

FIGURE 4: Comparative analysis on the crushing strength of pectin from various genotypes as disintegrants ((a) $5 \% \mathrm{w} / \mathrm{w}$, (b) $7.5 \% \mathrm{w} / \mathrm{w}$, and (c) $10 \% \mathrm{w} / \mathrm{w})$ and a standard disintegrant using $t$-test. Values are mean $\pm \mathrm{SD}(n=6) .{ }^{*} p \leq 0.05,{ }^{* *} p \leq 0.01,{ }^{* * *} p \leq 0.001,{ }^{* * * *} p \leq 0.0001$, and $p>0.05$ not significant (ns).

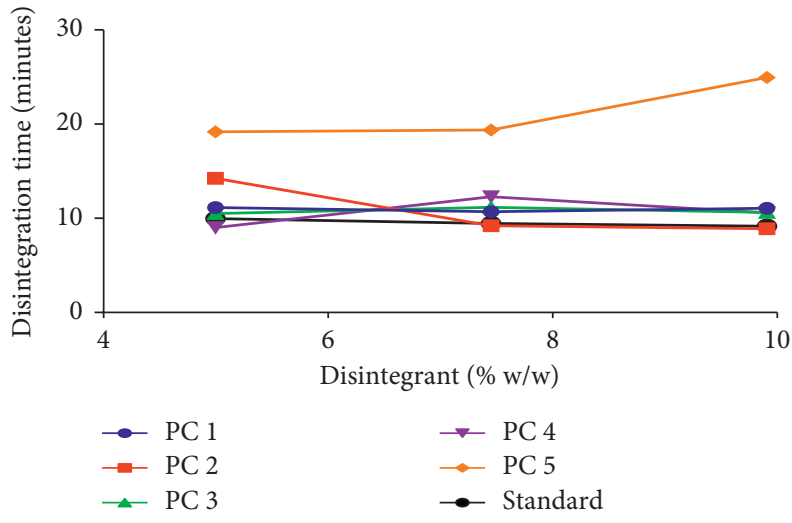

FIGURE 5: Effect of pectin concentrations as disintegrants on disintegration time.

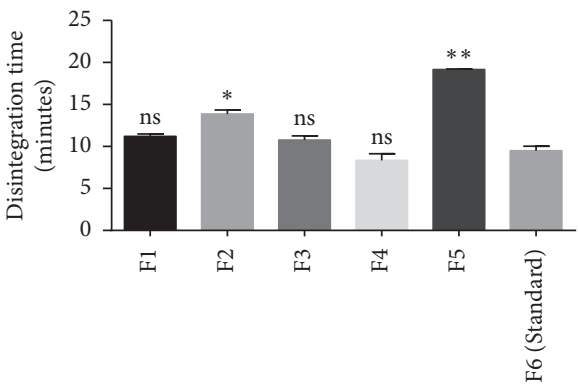

Formulation

(a)

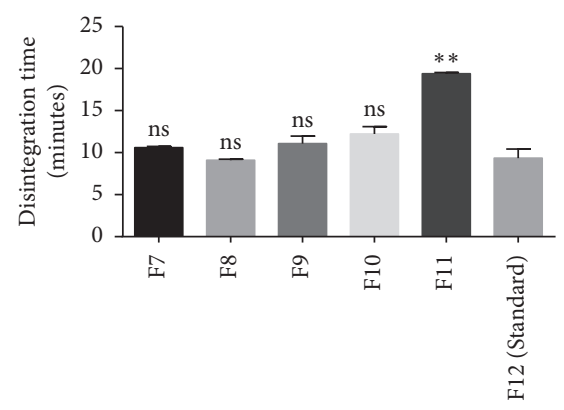

Formulation

(b)

Figure 6: Continued. 


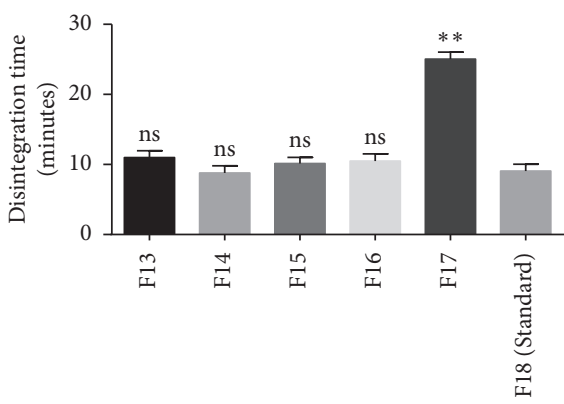

Formulation

(c)

Figure 6: Comparative analysis on the disintegration time of pectin from various genotypes as disintegrants ((a) 5\% w/w, (b) 7.5\% w/w, and (c) $10 \% \mathrm{w} / \mathrm{w})$ and a standard disintegrant using $t$-test. Values are mean $\pm \mathrm{SD}(n=2) .{ }^{*} p \leq 0.05,{ }^{* *} p \leq 0.01$, and $p>0.05$ not significant (ns).

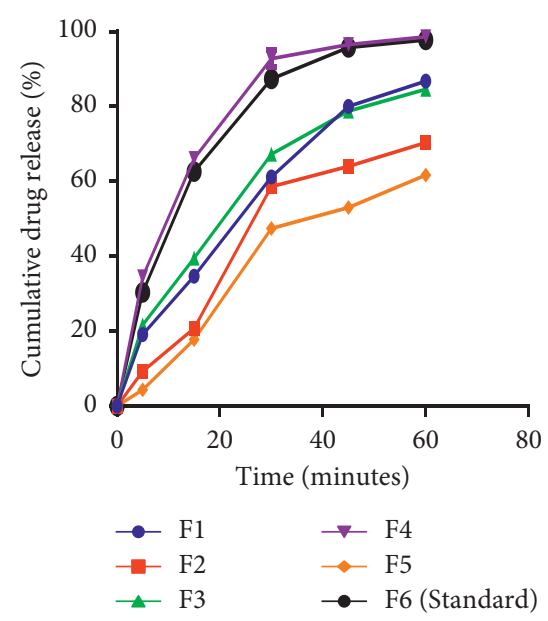

(a)

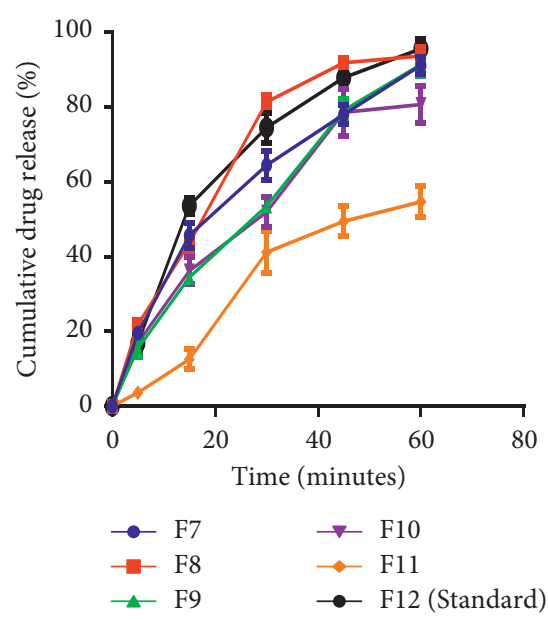

(b)

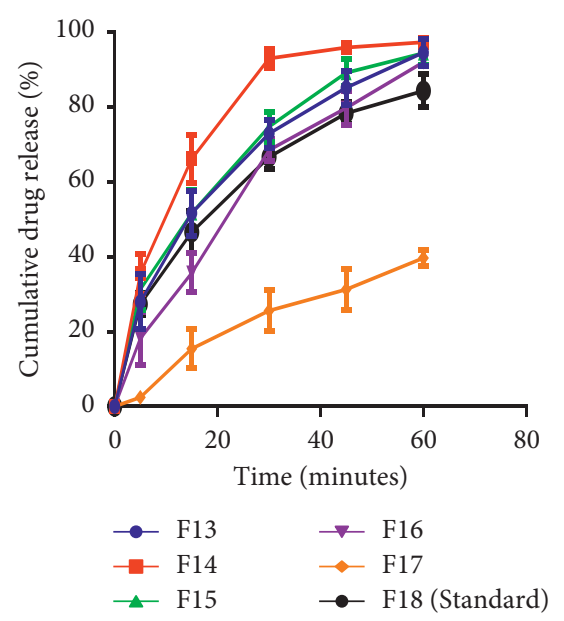

(c)

FIGURE 7: Dissolution profiles of formulated paracetamol tablets containing (a) 5\% w/w okra pectin, (b) 7.5\% w/w okra pectin, and (c) $\sim 10 \% \mathrm{w} / \mathrm{w}$ okra pectin in phosphate buffer $\mathrm{pH} 5.8($ mean $\pm \mathrm{SD}, n=3)$.

TABle 5: Difference $(f 1)$ and similarity $(f 2)$ factors of formulated batches.

\begin{tabular}{lccc}
\hline Formulation & Difference factor $(f 1)$ & Similarity factor $(f 2)$ & Comment \\
\hline F1 & 25.23 & 34.62 & Dissimilar \\
F3 & 21.86 & 38.18 & Dissimilar \\
F4 & 3.28 & 72.38 & Similar \\
F7 & 9.06 & 53.68 & Similar \\
F8 & 6.77 & 65.59 & Similar \\
F9 & 24.29 & 40.20 & Dissimilar \\
F10 & 20.74 & 39.94 & Dissimilar \\
F13 & 9.17 & 59.10 & Similar \\
F14 & 29.23 & 35.94 & Dissimilar \\
F15 & 12.6 & 53.8 & Similar \\
F16 & 10.21 & 56.44 & Similar \\
\hline
\end{tabular}


disintegrant concentration of $10 \% \mathrm{w} / \mathrm{w}$, okra pectins from PC1, PC3, and PC4 achieved similar paracetamol release as maize starch BP. The various okra pectins in their respective concentrations can be considered as alternate disintegrants to maize starch BP in the formulation of bioequivalent immediate release tablets [45]. Since these genotypes of okra are readily available in Ghana, their pectins can be harnessed and used to formulate bioequivalent products at a lower cost in comparison to the imported maize starch BP.

\section{Conclusion}

Variations in genotypes of okra have an influence on pectin yield. The extracted okra pectins contained negligible amounts of toxic metals and appreciable levels of micronutrients; hence, they can be used as potential pharmaceutical excipients. Pectins extracted from PC4, PC1, and PC3 when used as disintegrants in the range of $5-10 \% \mathrm{w} / \mathrm{w}$ exhibited good disintegrating properties in immediate release tablets and are comparable to maize starch BP. Pectin from PC2 produces good disintegrating properties in immediate release tablets within concentration ranges of 7.5-10\% w/w. Pectin extracted from PC5 does not possess the desired disintegrating properties in immediate release tablets within the concentrations used (5-10\% w/w). Pectin obtained from different genotypes of okra has an influence on its disintegrating and tablet formulation characteristics.

\section{Data Availability}

The data used to support the findings of this study are included in the article and also available from the corresponding author upon request.

\section{Conflicts of Interest}

The authors declare that there are no conflicts of interest regarding the publication of this paper.

\section{Acknowledgments}

The authors are grateful to the technical staff of the Department of Pharmaceutics and the Department of Horticulture, Kwame Nkrumah University of Science and Technology, for their technical support.

\section{References}

[1] N. Nattapulwat, N. Purkkao, and O. Suwithayapanth, "Evaluation of native and carboxymethyl yam (Dioscorea esculenta) starches as tablet disintegrants," Science, Engineering and Health Studies, vol. 2, pp. 18-25, 2008.

[2] F. K. Adjei, Y. A. Osei, N. Kuntworbe, and K. Ofori-Kwakye, "Evaluation of the disintegrant properties of native starches of five new cassava varieties in paracetamol tablet formulations," Journal of Pharmaceutics, vol. 2017, Article ID 2326912, 9 pages, 2017.

[3] M. E. Aulton and K. M. Taylor, Aulton's Pharmaceutics: The Design and Manufacture of Medicines, Vol. 3, Churchill Livingstone, London, UK, 2017.
[4] P. M. Desai, C. V. Liew, and P. W. S. Heng, "Review of disintegrants and the disintegration phenomena," Journal of Pharmaceutical Sciences, vol. 105, no. 9, pp. 2545-2555, 2016.

[5] T. Saha, Z. U. Masum, S. K. Mondal et al., "Application of natural polymers as pharmaceutical excipients," Global Journal of Life Sciences Biological Research, vol. 4, no. 1, pp. pp41-48, 2018.

[6] I. J. Ogaji, E. I. Nep, and J. D. Audu-Peter, "Advances in natural polymers as pharmaceutical excipients," Pharm Analyitca Acta, vol. 3, no. 146, p. 65, 2012.

[7] D. N. O. Kuevi, E. Ayertey, D. A. Bartels, and F. W. A. Owusu, "Evaluation of the disintegration properties of Khaya senegalensis gum using paracetamol tablets," Asian Journal of Research in Medical and Pharmaceutical Sciences, vol. 6, no. 3, pp. 1-8, 2019.

[8] B. Hartesi, Sriwidodo, M. Abdassah, and A. Y. Chaerunisaa, "Starch as pharmaceutical excipient," International Journal of Pharmaceutical Science Review and Research, vol. 41, no. 2, pp. 59-64, 2016.

[9] S. Goswami and S. Naik, "Natural gums and its pharmaceutical application," Journal of Scientific and Innovative Research, vol. 3, no. 1, pp. 112-121, 2014.

[10] J. Lu, J. Li, R. Jin, S. Li, J. Yi, and J. Huang, "Extraction and characterization of pectin from Premna microphylla Turcz leaves," International Journal of Biological Macromolecules, vol. 131, pp. 323-328, 2019.

[11] R. R. Shah, P. P. Gayakar, and M. M. Nitalikar, "Lemon peel as a potential source of pectin and it's use as application of pectin as binder in the formulation of tablets," Research Journal of Pharmacy and Technology, vol. 8, no. 12, pp. 1669-1672, 2015.

[12] M. Ravindrakullai Reddy and K. Manjunath, "Evaluation of pectin derived from orange peel as a pharmaceutical excipient," International Journal of Drug Development and Research, vol. 5, no. 2, pp. 283-294, 2013.

[13] R. Ciriminna, A. Fidalgo, G. Avellone et al., "Economic and technical feasibility of betanin and pectin extraction from opuntia ficus-indica peel via microwave-assisted hydrodiffusion," ACS Omega, vol. 4, no. 7, pp. 12121-12124, 2019.

[14] S. Bahadur, A. Roy, R. Chanda et al., "Natural excipient development: need and future," Asian Journal of Pharmaceutical Research, vol. 4, no. 1, pp. 12-15, 2014.

[15] O. A. Odeku, "Potentials of tropical starches as pharmaceutical excipients: a review," Starch/Staerke, vol. 65, no. 2, pp. 89-106, 2013.

[16] M. O. Emeje, C. Y. Isimi, and O. O. Kunle, "Evaluation of Okra gum as a dry binder in Paracetamol tablet formulations," Continental Journal of Pharmaceutical Sciences, vol. 1, pp. 15-22, 2007.

[17] A. Hussain, F. Qureshi, N. Abbas, M. S. Arshad, and E. Ali, "An evaluation of the binding strength of okra gum and the drug release characteristics of tablets prepared from it," Pharmaceutics, vol. 9, no. 2, p. 20, 2017.

[18] R. Kumar, M. B. Patil, S. R. Patil, and M. S. Paschapur, "Evaluation of disintegrating properties of Abelmoschus esculentus mucilage," International Journal of PharmTech Research, vol. 1, no. 2, pp. 241-246, 2009.

[19] M. E. Boakye-Gyasi, F. W. A. Owusu, P. Entsie, J. K. Agbenorhevi, B. K. B. Banful, and M. T. Bayor, "Pectin from okra (Abelmoschus esculentus L.) has potential as a drug release modifier in matrix tablets," The Scientific World Journal, vol. 2021, Article ID 6672277, 10 pages, 2021.

[20] F. M. Kpodo, J. K. Agbenorhevi, K. Alba et al., "Pectin isolation and characterization from six okra genotypes," Food Hydrocolloids, vol. 72, pp. 323-330, 2017. 
[21] K. Alba, A. P. Laws, and V. Kontogiorgos, "Isolation and characterization of acetylated LM-pectins extracted from okra pods," Food Hydrocolloids, vol. 43, pp. 726-735, 2015.

[22] World Health Organization, International Pharmacopoeia, World Health Organization, Geneva, Switzerland, 9th edition, 2019.

[23] M. A. Fosu, K. Ofori-Kwakye, N. Kuntworbe, and M. A. Bonsu, "Investigation of blends of cashew and xanthan gums as a potential carrier for colonic delivery of Ibuprofen," International Journal of PharmTech Research, vol. 9, no. 7, pp. 369-380, 2016.

[24] M. A. Bonsu, K. Ofori-Kwakye, S. L. Kipo, M. E. BoakyeGyasi, and M.-A. Fosu, "Development of oral dissolvable films of diclofenac sodium for osteoarthritis using albizia and khaya gums as hydrophilic film formers," Journal of Drug Delivery, vol. 2016, Article ID 6459280, 11 pages, 2016.

[25] R. Malviya and G. T. Kulkarni, "Extraction and characterization of mango peel pectin as pharmaceutical excipient," Indian Journal of Natural Products and Resources, vol. 2, no. 1, pp. 185-190, 2012.

[26] British Pharmacopoeia, and British Pharmacopoeia Commission, The Stationary Office, London, UK, 2018.

[27] United State Pharmacopoeia, USP 41: The National Formulary: NF 36, Vol. 41, United States Pharmacopoeial Convention, Rockville, MD, USA, 2018.

[28] N. Aminu, S.-Y. Chan, N. H. Khan, A. B. Farhan, M. N. Umar, and S.-M. Toh, "A simple stability-indicating HPLC method for simultaneous analysis of paracetamol and caffeine and its application to determinations in fixed-dose combination tablet dosage form," Acta Chromatographica, vol. 31, no. 2, pp. 85-91, 2019.

[29] M. Islam, V. Gupta, V. Singh Mahalwal, and T. Achalu, "Physico-chemical evaluation of four brands of paracetamol $500 \mathrm{mg}$ tablets by using quality control techniques," The Pharmaceutical and Chemical Journal, vol. 6, no. 4, pp. 89-96, 2019.

[30] D. Gawkowska, J. Cybulska, and A. Zdunek, "Structure-related gelling of pectins and linking with other natural compounds: a review," Polymers, vol. 10, no. 7, p. 762, 2018.

[31] N. Berardini, M. Knödler, A. Schieber, and R. Carle, "Utilization of mango peels as a source of pectin and polyphenolics," Innovative Food Science \& Emerging Technologies, vol. 6, no. 4, pp. 442-452, 2005.

[32] M. D. F. Sato, D. C. Rigoni, M. H. G. Canteri, C. L. D. O. Petkowicz, A. Nogueira, and G. Wosiacki, "Chemical and instrumental characterization of pectin from dried pomace of eleven apple cultivars," Acta Scientiarum. Agronomy, vol. 33, no. 3, pp. 383-389, 2011.

[33] N. C. Ngwuluka, B. A. Idiakhoa, E. I. Nep, I. Ogaji, and I. S. Okafor, "Formulation and evaluation of paracetamol tablets manufactured using the dried fruit of Phoenix dactylifera Linn as an excipient," Research in Pharmaceutical Biotechnology, vol. 2, no. 3, pp. 25-32, 2010.

[34] S. C. Gad, Pharmaceutical Manufacturing Handbook: Production and Processes, Vol. 5, John Wiley \& Sons, Hoboken, NJ, USA, 2008.

[35] R. I. Mahato and A. S. Narang, Pharmaceutical Dosage Forms and Drug Delivery, CRC Press, Boca Raton, FL, USA, 2011.

[36] S. N. Patere, C. J. Kapadia, and M. S. Nagarsenker, "Influence of formulation factors and compression force on release profile of sustained release Metoprolol tablets using Compritol ${ }^{\circledR}$ 888ATO as lipid excipient," Indian Journal of Pharmaceutical Sciences, vol. 77, no. 5, pp. 620-625, 2015.

[37] A. Ahmed, S. A. Ali, F. Hassan, S. Ayub, and N. Haque, "Effect of disintegrants and hardness on the disintegration time of
Acetaminophen tablets," Pakistan Journal of Pharmaceutical Sciences, vol. 11, no. 1, pp. 41-46, 1998.

[38] O. A. Odeku and C. O. Alabi, "Evaluation of native and modified forms of Pennisetum glaucum (millet) starch as disintegrant in chloroquine tablet formulations," Journal of Drug Delivery Science and Technology, vol. 17, no. 2, pp. 155-158, 2007.

[39] O. J. Uwaezuoke, O. A. Bamiro, N. C. Ngwuluka, O. T. Ajalla, and A. O. Okinbaloye, "Comparative evaluation of the disintegrant properties of rice husk cellulose, corn starch and avicel in metronidazole tablet formulation," Journal of Applied Pharmaceutical Science, vol. 4, no. 12, pp. 112-117, 2014.

[40] M. Saleem, M. Shahin, B. Srinivas, and A. Begum, "Evaluation of tablets by friability apparatus," International Journal of Research in Pharmacy and Chemistry, vol. 4, no. 4, pp. 837840, 2014.

[41] M. J. Kottke and E. M. Rudnic, "Tablet dosage forms," in Modern Pharmaceutics, pp. 458-532, CRC Press, Boca Raton, FL, USA, 2002.

[42] C. G. Mukesh, G. S. Krishnakant, R. M. Neelima, D. S. Chirag, U. V. Vinita, and K. D. Rikita, "Assessment of similarity factor using different weighing approaches," Dissolution Technologies, vol. 12, no. 4, pp. 22-27, 2005.

[43] J. Ocaña, G. Frutos, and P. Sánchez O, "Using the similarity factor in practice: a critical revision and suggestions for its standard error estimation," Chemometrics and Intelligent Laboratory Systems, vol. 99, no. 1, pp. 49-56, 2009.

[44] P. Costa and J. M. Sousa Lobo, "Modeling and comparison of dissolution profiles," European Journal of Pharmaceutical Sciences, vol. 13, no. 2, pp. 123-133, 2001.

[45] J. J. Darrow, J. Avorn, and A. S. Kesselheim, "FDA approval and regulation of pharmaceuticals, 1983-2018," JAMA, vol. 323 , no. 2 , pp. 164-176, 2020. 